\title{
Acute myocardial infarction due to coronary stent thrombosis in a symptomatic COVID-19 patient
}

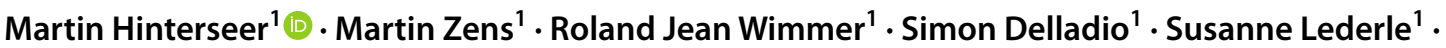 \\ Christian Kupatt $^{2,3} \cdot$ Bernd Hartmann $^{4}$
}

Received: 15 April 2020 / Accepted: 5 May 2020 / Published online: 19 May 2020

○) Springer-Verlag GmbH Germany, part of Springer Nature 2020

Keywords COVID-19 $\cdot$ Acute myocardial infarction $\cdot$ Stent thrombosis $\cdot$ Respiratory failures

Sirs:

A 65-year-old gentleman presented to our hospital with fever, dry cough and body aches and a presumed respiratory tract infection. His past medical history included coronary heart disease and myocardial infarction 4 years previously due to marginal branch occlusion. This initial lesion was treated by stenting of the marginal branch and LAD (2.5/16 $\mathrm{mm}$ and 3.0/22 $\mathrm{mm}$ drug eluting stents; Zotarolimus/ ABT-578). Two years after the first stent implantation, neointimal proliferation required a second drug-eluting stent of the marginal branch stent $(2.75 / 16 \mathrm{~mm}$, Everolimus). The patient's risk profile comprised type 2 diabetes mellitus, arterial hypertension and hyperlipidaemia.

At admission, the initial vital parameters and laboratory results were: Temp. $39.0^{\circ} \mathrm{C}$, White Blood Cell count $3.91 \times 10^{12}$ cells $/ 1$, Haemoglobin $12.8 \mathrm{~g} / \mathrm{dl}$, creatinine $1.44 \mathrm{mg} / \mathrm{dl}$, eGFR $52.2 \mathrm{ml} / \mathrm{m} / 1.73 \mathrm{~m}^{2}$, C-reactive protein $61.4 \mathrm{mg} / \mathrm{dl}, \mathrm{LDH} 413 \mathrm{U} / \mathrm{l}, \mathrm{CK} 130 \mathrm{U} / \mathrm{l}$, procalcitonin (PCT)

Electronic supplementary material The online version of this article (https://doi.org/10.1007/s00392-020-01663-4) contains supplementary material, which is available to authorized users.

Martin Hinterseer

martin.hinterseer@kliniken-oal-kf.de

1 Department of Medicine, Heart Center Fuessen-Ausserfern, Fuessen Hospital, Kliniken Ostallgaeu-Kaufbeuren, Stadtbleiche 1, 87629 Fuessen, Germany

2 Internal Medicine I, University Clinic Rechts Der Isar, TUM Munich, Munich, Germany

3 DZHK (German Cardiovascular Research Centre), Partner Site Munich Heart Alliance, Munich, Germany

4 Department of Anesthesia and Intensive Care, Fuessen Hospital, Kliniken Ostallgaeu-Kaufbeuren, Stadtbleiche 1, Fuessen, Germany
$0.08 \mathrm{ng} / \mathrm{ml}$, oxygen saturation $92 \%$ at room air. These were consistent with acute respiratory tract infection. A routine ECG demonstrated sinus rhythm with normal heart rate, without bundle branch block or ST-alterations (Fig. 1a). Chest X-ray revealed diffuse bilateral pulmonary infiltrates (Fig. 2). Echocardiography upon admission confirmed a regular left ventricular ejection fraction of approximately $67 \%$ without any regional wall motion abnormalities.

The patient's regular medication consisted of aspirin $100 \mathrm{mg}$ OD, candesartan $16 \mathrm{mg}$ OD, bisoprolol $2.5 \mathrm{mg}$ OD, atorvastatin $40 \mathrm{mg} \mathrm{OD}$, ezetimibe $10 \mathrm{mg} \mathrm{OD}$, empagliflozin $10 \mathrm{mg}$ OD and metformin $2000 \mathrm{mg}$ daily. Oropharyngeal and nasopharyngeal swabs were positive for SARS-CoV-2 on real-time reverse transcriptase-polymerase testing. The patient additionally received enoxaparin sodium $40 \mathrm{mg} /$ day to prevent deep vein thrombosis.

After initial improvement of clinical symptoms, the patient complained of acute respiratory distress on day 3 . The peripherally measured oxygen saturation had dropped to $78 \%$ despite oxygen delivered at $121 / \mathrm{min}$ were administered via a non-reservoir oxygen mask. Repeat laboratory values were: creatinine $1.17 \mathrm{mg} / \mathrm{dl}$, eGFR $66.7 \mathrm{ml} / \mathrm{m} / 1.73 \mathrm{~m}^{2}$, troponin T $105.3 \mathrm{pg} / \mathrm{ml}$, CK $347 \mathrm{U} / \mathrm{l}$, BNP $3054 \mathrm{pg} / \mathrm{ml}$ ).

The patient was immediately transferred to ICU and an invasive ventilation initiated. Shortly after intubation, ventricular fibrillation occurred and was successfully terminated by electrical defibrillation. ECG recording (Fig. 1b) revealed a complete right bundle branch block with ST-elevation in lead aVR. Echocardiography revealed a severely reduced left ventricular ejection fraction without valve impairment. A right heart strain or pericardial effusion was excluded. The patient then underwent urgent coronary angiography. Norepinephrine $1.8 \mu \mathrm{g} \mathrm{kg}^{-1} \mathrm{~min}^{-1}$ was sufficient to maintain a mean arterial blood pressure of $60 \mathrm{mmHg}$. The coronary angiography (Fig. 3) revealed a proximal occlusion of the 


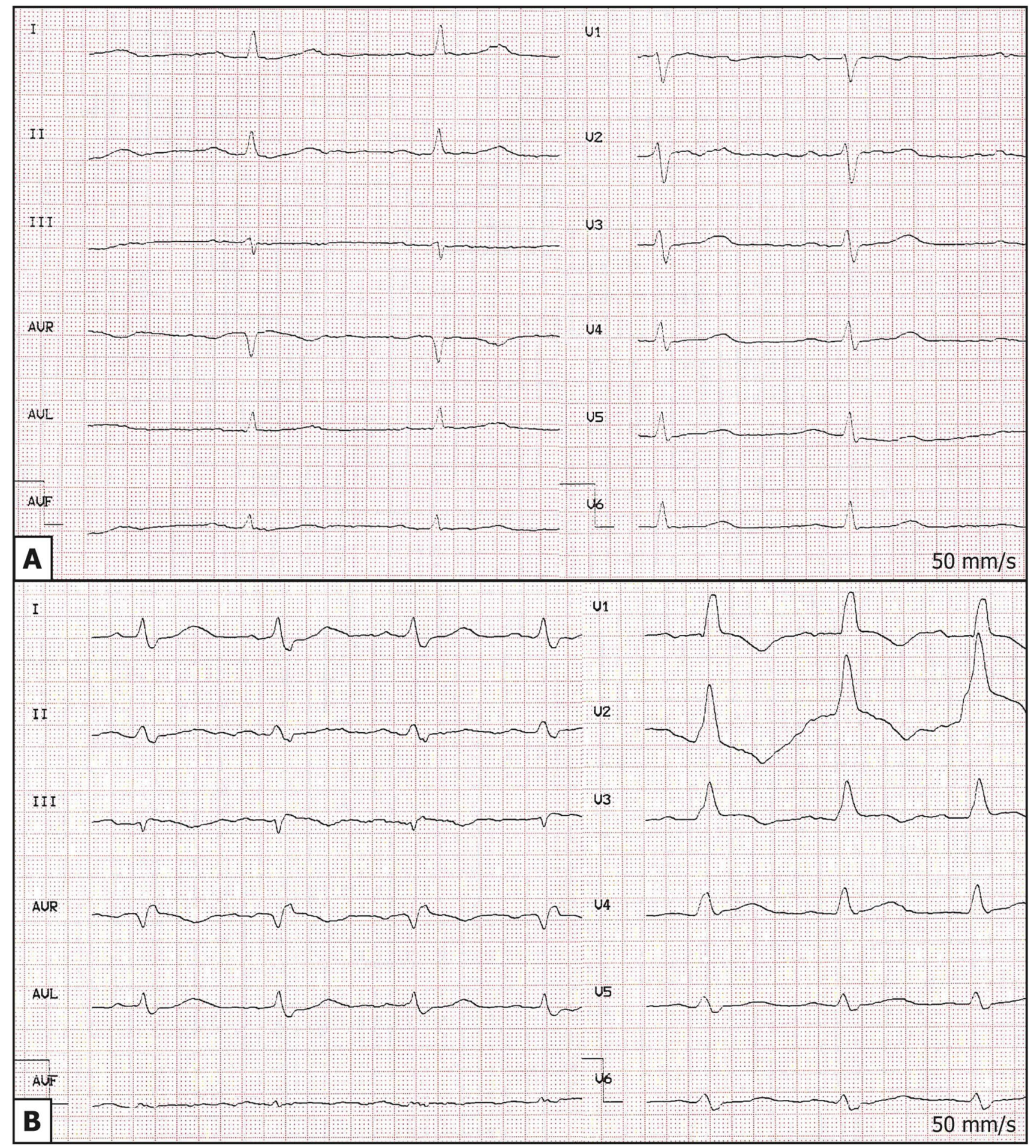

Fig. 1 a 12-lead ECG recording on admission with normal sinus rhythm. b Complete right bundle branch block and an ST-elevation in lead aVR

left anterior descending artery (LAD) in a stented segment. After successful recanalization utilizing balloon dilation followed by stenting with a $3.0 / 28 \mathrm{~mm}$ and a $2.5 / 15 \mathrm{~mm}$ drug eluting stent (Zotarolimus/ABT-578), TIMI III flow was documented. Antiplatelet therapy with tirofiban and prasugrel was commenced and the loading dose applied immediately. The dual anti-platelet therapy with aspirin and prasugrel was administered via an orogastric tube. On ICU, a hemodynamic measurement system $\left(\mathrm{PiCCO}^{\circledR}\right.$, Pulsion Medical Systems AG, Munich, Germany) was established to 


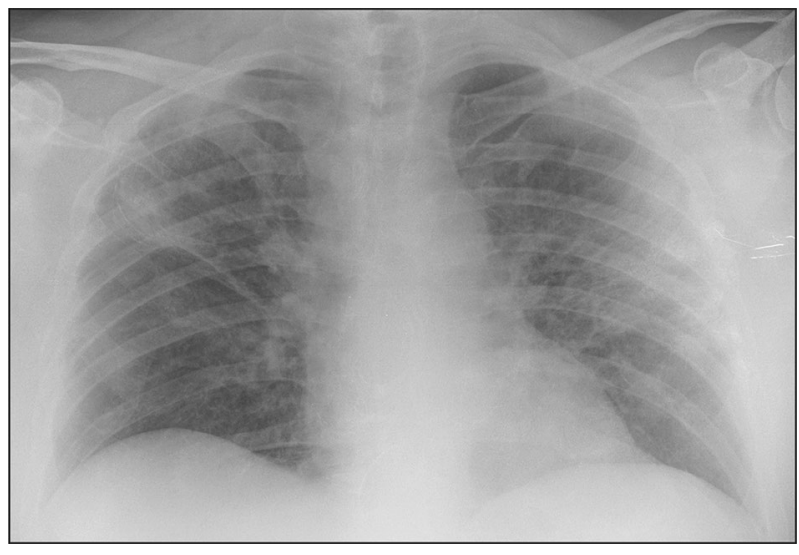

Fig. 2 Chest X-ray with diffuse bilateral pulmonary infiltration

adjust catecholamine doses and control fluid management. A post-interventional echocardiogram showed a left ventricular ejection fraction of approximately $35 \%$. The cardiac power index (CPI) continuously stayed below $0.4 \mathrm{~W} / \mathrm{m}^{2}$ over the first 5 days on ICU corresponding to a significantly reduced cardiac performance associated with poor prognosis. Lab results on day 1 post PCI were: creatinine $1.85 \mathrm{mg} / \mathrm{dl}$, eGFR $39.3 \mathrm{ml} / \mathrm{m} / 1.73 \mathrm{~m}^{2}$ troponin $\mathrm{T}>10,000 \mathrm{pg} / \mathrm{ml}, \mathrm{CK} 4570 \mathrm{U} / \mathrm{l}$. The rising requirement for norepinephrine led to levosimendan being administered $\left(0.1 \mu \mathrm{g} \mathrm{kg}^{-1} \mathrm{~min}^{-1}\right.$ for $\left.48 \mathrm{~h}\right)$. An episode of atrial fibrillation with a short hemodynamic worsening was treated successfully by electric cardioversion and cardiac rhythm was stabilised with amiodarone administration. After levosimendan was given, a short rise of CPI up to 0.43 on day 6 occurred.

In summary, hemodynamic measurement revealed a mixed form of septic and cardiac shock due to septic and ischemic cardiomyopathy. On day 5 cyanosis of the extremities appeared and became more noticeable in subsequent days. Surprisingly, this was not associated with a significant increase of serum lactate levels, which remained between 1.0 and $2.5 \mathrm{mmol} / \mathrm{l}$ throughout the whole course of his admission to ICU. An association with norepinephrine use remained difficult to establish regarding doses mostly around $0.4 \mu \mathrm{g} \mathrm{kg}^{-1} \mathrm{~min}^{-1}$ culminating in day 2 at values around $0.7 \mu \mathrm{g} \mathrm{kg}^{-1} \mathrm{~min}^{-1}$, which were significantly reduced after levosimendan administration. No evidence was obtained for disseminated intravascular coagulopathy (DIC). On day 5, a continuous decrease of renal activity (creatinine $3.95 \mathrm{mg} / \mathrm{dl}$, eGFR $16.4 \mathrm{ml} / \mathrm{m} / 1.73 \mathrm{~m}^{2}$ ) and oliguria of less than $20 \mathrm{ml} /$ hour resulted in commencement of veno-venous hemodiafiltration with citrate (CVVHD-Ci-Ca). An acute renal failure occurred in association with a bacterial superinfection implied by rising procalcitonin levels $(0.96 \mathrm{ng} / \mathrm{ml})$ in the general context of a rapidly progressing multi organ failure. The patient was given antibiotic therapy with azithromycin $(500 \mathrm{mg} /$ day $)$ and piperacillin/tazobactam $(4.0 \mathrm{~g}+0.5 \mathrm{~g}$; four doses per day). The patient was sedated and ventilated (pressure-controlled ventilation, BIPAP-mode). The oxygenation index indicated a severe ARDS in line with the Berlin Definition of ARDS. In the subsequent days the oxygenation improved slightly.

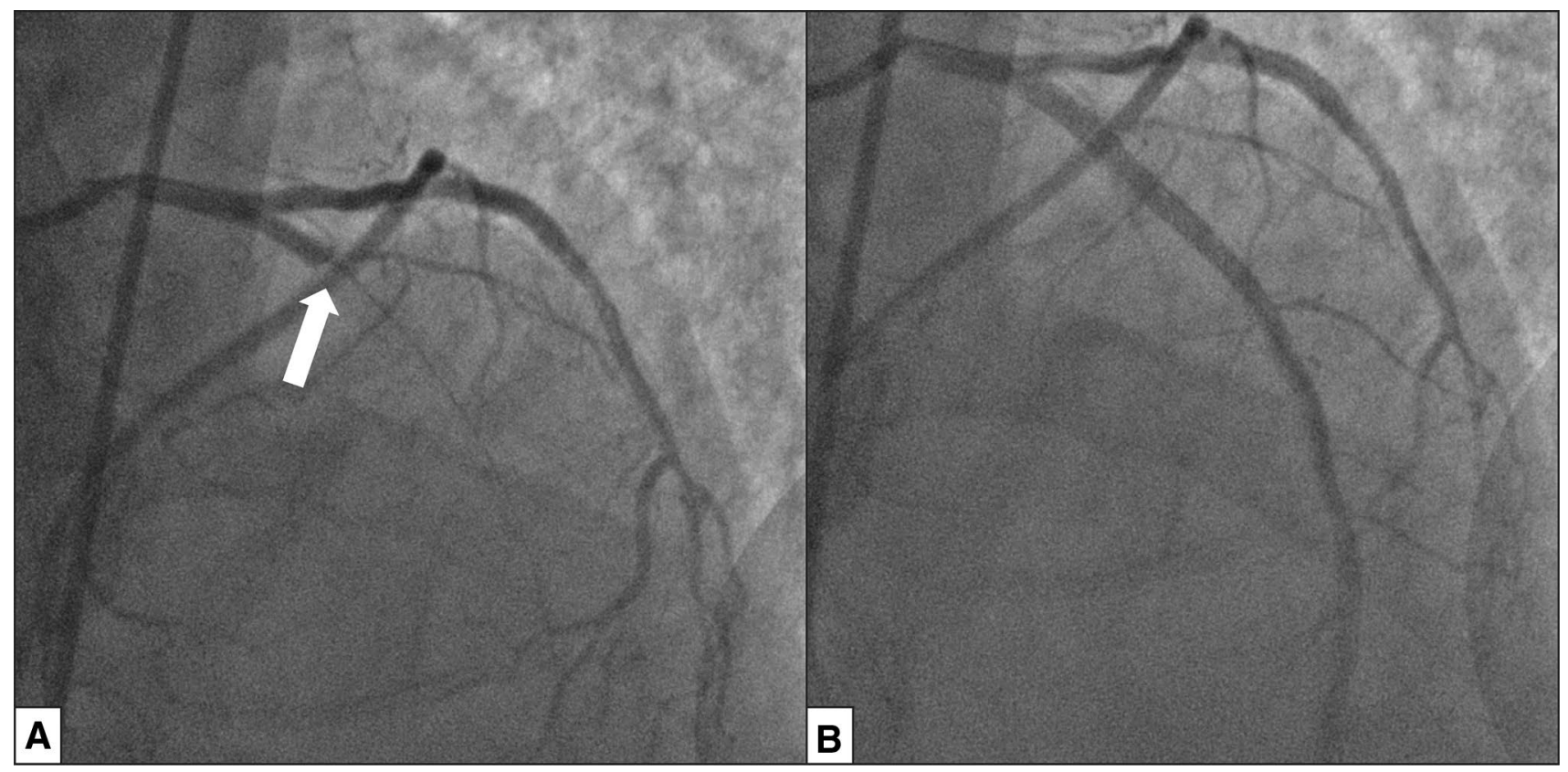

Fig. 3 a Coronary angiography with $0-40$ cranial angulation and documented total occlusion of the left anterior descending artery (LAD) in a stent segment. b Coronary angiography with 0-40 cranial angulation after revascularization with TIMI III flow 
In addition to the respiratory aspect a prolonged reduction of cardiac power in spite of levosimendan therapy and a low systemic vascular resistance made the hemodynamic situation unfavourable for use of a VA-ECMO. Nevertheless, hypoxemia remained the major problem, even in the context of an escalated ventilation with worsening oxygenation. On day 11 after admission to our hospital and on day 8 after admission to ICU, it was agreed that there should be no further escalation in treatment and only supportive care should be offered. The patient died later due to multi organ failure.

This report describes the case of a 65 -year old male patient with acute myocardial infarction due to a documented stent thrombosis in a symptomatic COVID-19 patient. Insufficient data exist regarding the extent to which coronary artery disease contributes to morbidity and mortality of COVID-19 patients. Shaobo et al. [1] recently reported an association between COVID-19 infection and cardiac injury, resulting in a higher risk of in-hospital mortality than with either condition alone. The mechanisms of this observation remain uncertain. Previous research has demonstrated that influenza and other viral diseases precipitate coronary spasm, plaque ruptures or stent thrombosis by tachycardia, hypoxia, increased wall stress, procoagulation or inflammatory cytokine release [2-5]. Consistently, the term immunothrombosis was coined to describe thrombotic events triggered by inflammatory reactions [6]. A recent publication by Zhang et al. [7] describe the presence of antiphospholipid antibodies in COVID-19 patients, which may lead to thrombotic events. In this regard, the necessity of antiplatelet therapy or intensifying an established therapy in COVID-19 patients with pre-existing coronary heart disease or a history of stenting, especially recent stenting, remains the goal of further research.

Thus, a sudden onset of an unstable respiratory or hemodynamic condition in COVID-19 patients may be the symptomatic equivalent of an acute heart failure due to ischemia (as in our case) or myocarditis [8] and not necessarily due to a worsening of the pulmonary condition. Li et al. [9] report that $8.0 \%$ of COVID-19 patients suffer acute cardiac injury.

However, not all COVID patients presenting with deteriorating cardiac function display coronary artery disease. In contrast, a non-vascular cardiomyopathy with high troponin levels and accompanying ECG alterations has been described as a potential result of the cytokine storm in these patients, with high levels of interleukin- 6 predicting worse prognosis [10].

Of note, the current STEMI guidelines consider a new complete right bundle branch block as sign of acute myocardial infarction [11]. In the treatment of COVID-19 patients, ECG and echocardiography are essential for rapid diagnosis and should be available on isolation wards and intensive care units. This case emphasizes the importance of cardiac monitoring and echocardiography which is of high relevance in all COVID-19 patients with rapid progression of symptoms. Stent thrombosis is a dramatic complication of coronary stenting, presenting as sudden death or acute myocardial infarction if missed or misdiagnosed [12]. An immediate revascularization is essential in order to prevent long-term cardiac impairment or death [13]. In COVID-19 patients, this even more important than in patients without accompanying diseases.

Acknowledgements The authors would like to thank Dr. Rabnawaz Khan for proofreading of the manuscript.

Author contributions All authors had access to the data and a role in writing this manuscript.

Funding Dr. Hinterseer is supported by a grant from Arbeitsgemeinschaft Leitende Kardiologische Krankenhausärzte e.V. (ALKK).

\section{Compliance with ethical standards}

Conflict of interest All authors agreed to submit this case report and declared no conflict of interest.

\section{References}

1. Shi S et al (2020) Association of cardiac injury with mortality in hospitalized patients with COVID-19 in Wuhan, China. JAMA Cardiol. https://doi.org/10.1001/jamacardio.2020.0950

2. Barnes $\mathrm{M}$ et al (2015) Acute myocardial infarction and influenza: a meta-analysis of case-control studies. Heart 101(21):1738-1747. https://doi.org/10.1136/heartjnl-2015-307691

3. Hebsur S et al (2014) Influenza and coronary artery disease: exploring a clinical association with myocardial infarction and analyzing the utility of vaccination in prevention of myocardial infarction. Rev Cardiovasc Med 15(2):168-175. https://doi. org/10.3909/ricm0692

4. Guan X et al (2012) Association of influenza virus infection and inflammatory cytokines with acute myocardial infarction. Inflamm Res 61(6):591-598. https://doi.org/10.1007/s00011-012-0449-3

5. Madjid M et al (2007) Systemic infections cause exaggerated local inflammation in atherosclerotic coronary arteries: clues to the triggering effect of acute infections on acute coronary syndromes. Tex Heart Inst J 34(1):11-18

6. Engelmann B, Massberg S (2013) Thrombosis as an intravascular effector of innate immunity. Nat Rev Immunol 13(1):34-45. https ://doi.org/10.1038/nri3345

7. Zhang Y et al (2020) Coagulopathy and antiphospholipid antibodies in patients with Covid-19. N Engl J Med 382:e38. https://doi. org/10.1056/NEJMc2007575

8. Inciardi RM et al (2020) Cardiac involvement in a patient with coronavirus disease 2019 (COVID-19). JAMA Cardiol. https:// doi.org/10.1001/jamacardio.2020.1096

9. Li B, Yang J, Zhao F, Zhi L, Wang X, Liu L, Bi Z, Zhao Y (2020) Prevalence and impact of cardiovascular metabolic diseases on COVID-19 in China. Clin Res Cardiol. https://doi.org/10.1007/ s00392-020-01626-9 (Epub ahead of print, PMID: 32161990)

10. Akhmerov A, Marban E (2020) COVID-19 and the heart. Circ Res. https://doi.org/10.1161/CIRCRESAHA.120.317055 
11. Ibanez B, James S (2018) The 2017 ESC STEMI guidelines. Eur Heart J 39(2):79-82. https://doi.org/10.1093/eurheartj/ehx753

12. Varenhorst C, Lindholm M, Sarno G, Olivecrona G, Jensen U, Nilsson J, Carlsson J, James S, Lagerqvist B (2018) Stent thrombosis rates the first year and beyond with new- and old-generation drug-eluting stents compared to bare metal stents. Clin Res Cardiol 107(9):816-823. https://doi.org/10.1007/s00392-018-1252-0
13. Backhaus SJ, Kowallick JT, Stiermaier T, Lange T, Koschalka A, Navarra JL, Lotz J, Kutty S, Bigalke B, Gutberlet M, Feistritzer HJ, Hasenfuß G, Thiele H, Schuster A, Eitel I (2020) Culprit vessel-related myocardial mechanics and prognostic implications following acute myocardial infarction. Clin Res Cardiol 109(3):339-349. https://doi.org/10.1007/s00392-019-01514-X 